\title{
The Role of Stress in Optimizing Surgical Performance
}

\author{
Adam M. Ali
}

Published online: 20 October 2011

(c) Société Internationale de Chirurgie 2011

In their evaluation of a method that assesses surgical workload, Wilson et al. [1] made the assumption that intraoperative stress is necessarily detrimental to surgical performance. However, the Yerkes-Dodson law [2] dictates that increasing levels of stress improve performance up to a point, beyond which further stress causes performance to diminish. Thus, if our objective is to improve outcomes, the important metric is not surgeons' subjective evaluation of their stress level but an objective evaluation of how different intraoperative conditions impact upon performance, especially given that the stress-performance relationship will differ between surgeons.

\section{References}

1. Wilson MR, Poolton JM, Malhotra N, Ngo K, Bright E, Masters RS (2011) Development and validation of a surgical workload measure: the Surgery Task Load Index (SURG-TLX). World J Surg 35:1961-1969. doi:10.1007/s00268-011-1141-4

2. Yerkes RM, Dodson JD (1908) The relation of strength of stimulus to rapidity of habit-formation. J Comp Neurol Psychol 18:459-482

A. M. Ali (ه)

Frank Knox Fellow, Harvard University, Cambridge, MA, USA

e-mail: adamali@post.harvard.edu 